\title{
TYPOLOGY OF INSURANCE BEHAVIOR OF RUSSIAN CITIZENS
}

\author{
Olga Medyanik \\ Department of Political Psychology, St. Petersburg state University (Russia)
}

\begin{abstract}
Ensuring the economic security of the personality is to create a mechanism of protection against internal and external threats in modern Russia. In this connection, the role of the policy of insurance of citizens as the most effective institution of risk management and security of health, personal property of citizens. The article presents the results of an empirical study of the attitude of Russian citizens to insurance policy of insurance and investment. The study consisted of three stages: at the preparatory stage - a longitudinal study of Russian clients of insurance companies was conducted, at the pilot study - a survey of policyholders on two developed scale multifactorial questionnaires investigating insurance preferences and financial anxiety. In the main study, which was presented by a heterogeneous sample, an Arsenal of techniques was used, which included a basic survey, a TAS questionnaire (in Soldatova's approbation), a questionnaire of economic attitudes (Deineka, Zabelin) and a Dinner satisfaction scale. A total of 1409 people took part in the study.

The article presents the results of theoretical understanding of the factors of economic security of the personality, which affect the insurance behavior of citizens. The questions of scientific development of insurance research in politics and Economics, the problem of psychology of personal security in the economy, the phenomenon of insurance in the economic life of the citizen and the phenomenon of trust as an indicator of political and economic reality. The problem of insurance culture and financial planning as a measure to reduce economic risks at the level of the state and the individual is raised. The theoretical model of insurance behavior is developed.

The Institute of insurance in our work is considered in the framework of psychological science as a category of risk avoidance, danger, threat, overcoming fear, as a system of economic security, creating a mechanism to protect the individual from internal and external fears and threats.
\end{abstract}

Keywords: Insurance behavior, insurance risks, economic security of the person, the typology of the insured, financial anxiety.

\section{Introduction}

In nowadays conditions, insurance provides the opportunity for market system of economic management to work in any state. To provide economic security of the person it is needed to create a mechanism of protection against internal and external threats in modern Russia. That's why the role of citizens insurance policy is increasing as the most effective risk management institute and achieving safety of health and private property of citizens

The goal of this research is to study Russian citizens' attitudes towards insurance policy and investment using the conception of personal economic security.

Theoretical analysis of insurance policy psychological problems has formed the basis for searching the case of pretty low preparedness of citizens to use the range of insurance service to advance personal economic security. The low level of confidence in private companies and banks, and the lack of financial literacy may be seen as the main reasons of restrained insurance behavior.

\section{Methods}

The preparatory study stage was focused on theoretical understanding of economic security problems taking insurance field as an example. Empirical research consisted of three stages. At the preparatory stage, the research was conducted of Russian insurance companies clients using longitudinal observation and interviews.

At the stage of pilot study insurance preferences and financial anxiety of citizens were measured using official Multiphase scale Inventories. 
At the stage of the main research characteristics of the attitude of citizens to the economic policy of the Russian Federation and, in particular, to the policy of insurance and investment was being studied. On the third and the main stage the characteristics of citizens' relations to economic of Russian federation and mainly to insurance and investment policy were studied using authorial method "CRPII" and economic attitudes (Deyneka's and Zabelina's inventory). Such personality characteristics as tolerance/intolerance to ambiguity were measured additionally using Bunder's TAS inventory in Soldatova's adaptation, life satisfaction using E.Diners method in Leontieva's and Osina's adaptation, economic attitudes (Dejneka's and Zabelina's iventory).

There were 1409 people taking part in this research.

\section{Results and discussion}

Basing on a theoretical understanding of the factors of personal economic security which are affecting the insurance behavior of citizens, on analysis of problems of confidence in Russian economics, insurance culture and financial planning as economic risk reduction remedy for the whole country and for the personality we worked out a theoretical model of insurance behavior.

Longitudinal observation of insurant behavior incombination with an unstructured interview during eight years (the first stage) allowed to work out a typology of insurant behavior based on psychology. Four types of insurants are marked out: sensible, confiding, anxious and risky.

A pilot study was made using the inventory of citizens' preferences in insurance (Deyneka's inventory algorithm) and the inventory of financial (second stage). It allowed us to transform the typology supplementing its foundations with the attitude characteristics to the economic policy of the Russia.

Exploratory factor analysis of the data received from inventory of citizens' preferences in insurance policy allowed to mark out two orthogonal factors: voluntaristic/fatal investment policy factor and paternalistic/market-oriented policy factor, which lay the foundation to correct typology that we got in the result of first stage of the research.

Also, two more factors were marked out, such as: seeking-oriented factor of insurants activity and reason factor, which holds back insurance policy. There were marked out three factors based on factor analysis inventory of financial anxiety. Such as financial anxiety factor, lack of money experience factor, value of insurance security factor.

Basing on received data it is advisable to consider the insurance institute not only as an economic functional, but also as a psychological and political institution that helps to reduce the experience of fear, danger, risk, as a system of economic security which creates a mechanism of personality protection from internal and external threats.

At the third stage of the research was worked out an inventory which made it possible to study the attitude of citizens to insurance and investment policies in the context of attitudes toward domestic economic policy in general. The study carried out with its help gave grounds to confirm the typology of citizens on the basis of their attitude to insurance and investment policies: paternalists, marketers, fatalists, voluntarists.

Additional methods of assessment of person's tolerance (Soldatova) and satisfaction with the quality of life (Diner) allowed me to carry out correlational analysis of psychological indicators and relation to economical policy of the government. Correlation analysis showed that the higher the tolerance to novelty, the less the need to insure the property and expand insurance through non-state and voluntary insurance services.

Relationships of life satisfaction with attitudes towards economic policy were revealed. The higher the satisfaction with life, the more positive is the attitude towards the results of economic policy in Russia (the welfare of citizens, the fairness of the tax system, satisfaction with consumption, the balance of effort and income, expectations of an increase in well-being).

The correlation of the data received from the inventory of attitudes towards insurance and investment policies and data from the inventory of economic policy confirmed the reliability of the research results. For example, the radical attitudes of those who represent the economic institutions of insurance and investment are associated with the condemnation of entrepreneurship and dissatisfaction with their consumer possibilities.

\section{Conclusions}

1. The program of the research of relation is developed and approved of citizens to the insurance policy, which included the design of the longitudinal research using the method of observation and semi-structured individual interviews with insurance clients companies and more scale multifactor questionnaire of citizens' preferences in insurance policy, financial anxiety, attitudes citizens to the 
policy of insurance and investment (the questionnaire CRPII) in combination with tested questionnaires of other authors-methods of economic attitudes (Deyneka, Zabelina), the scale of tolerance-intolerance identity uncertainty (Budner, adaptation of Soldatova), scale life satisfaction (Diner) for both topical and potential policyholders.

2. The results of the study of the attitude of Russian citizens to politics insurance and investment showed a contradictory attitude of citizens to insurance policy and lack of psychological readiness to shift economic risks to insurance companies.

3. The use of the term "economic security" is justified personality" as a long-term state of personal financial stability provisions for the manifestation of external and internal threats to the personal financial sovereignty, independence, capacity for economic development that provides the opportunity to meet and expand economic need.

4. Longitudinal monitoring of the behavior of insurance consumers services allowed to develop a typology of policyholders, which included four types: rational, anxious, trusting, risky. Describe there are also four types of strategies of insurance behavior: rational and alarming, rational-risky, anxious-trusting, risky-trusting.

5. Factor structure of preferences in insurance policy, obtained on the sample of actual policyholders, contains the factor market installation, the paternalistic factor installation factor tentatively-search activity, the factor of financial literacy, factor of the reasons constraining insurance policy. Cluster analysis of empirical data confirmed the presence of three types of policyholders: "marketers", "paternalists" and "neutral". "Paternalists" link the problems of the insurance industry and distrust of insurance companies with poor state control of activities insurance companies and other financial institutions, as well as the lack of fair distribution of income of the population. For such citizens the need to adopt fair economic policies is important laws'. "Marketers" distance themselves from the request for state control. The third category - "neutral" - are those insurers who are clearly not trust market institutions, but also to the role of the state are without special hope.

6. The factor structure of the financial anxiety questionnaire included factors affecting situational behavior that is associated with the loss of money, experiences of their deficit, awareness of investment risks, needs insurance coverage, financial optimism. Financial anxiety and uncertainty triggers consumer interest in insurance and investment products that can give him confidence in tomorrow and get rid of the feelings of ruin or loss of property.

7. Analysis of gender differences in attitudes towards economic policy showed that women have higher social internality than men. They are more likely to attribute blame for the problems in the country's economy citizens and more trust the policy pursued state. Women, unlike men, advocate for targeted assistance in preferential security policy. They believe that benefits should be received only families in need. Women are more prone to stability and conservatism, trusting and "socially naive", men-more are prone to risk and rational strategies in economic behavior.

8. Empirical research has shown that tolerant (positive) the attitude of citizens to insurance is a factor of increase economic security and tolerance to the economic situation uncertainty: more tolerant to uncertainty citizens will find themselves more satisfied with economic policy of their country. As there is a relationship between satisfaction life and attitude to economic policy: the higher satisfaction with life, the more positive attitude to the results economic policy in Russia.

9. The results of the study conducted on a sample of relevant and potential policyholders, confirmed the typological differences, obtained in the study of current policyholders.

The typology dividing citizens into "paternalists" is confirmed", "marketers" and "neutral" in relation to different aspects economic policy, including insurance was made.

10. On the basis of the theoretical analysis the generalizing the structure of the concepts of insurance behavior of a citizen in modern market economy, where the basis of perception of financial well-being is the economic security of the individual. A conceptual framework is proposed model of studying insurance behavior as a factor of economic security of person. The author's vision of the key elements is proposed effective insurance policy, taking into account the psychological aspects of modern Russia.

11. On the basis of the generalized structure of the concepts of insurance behavior and the empirical study of the attitude to politics insurance designed tiered structure that favors formation of insurance trust of citizens, including the block of financial anxiety, the unit value of insurance coverage, block financial literacy, insurance culture, economic security unit persons (in the context of insurance trust). 


\section{References}

Bazanov A. N. etc. (total 19 people) Insurance and risk management (textbook) for students / under the editorship of G. V. Chernova. - 2nd ed., - M.: yurait publishing House, 2014.

Belozerov S. A. The influence of insurance on the choice of the savings strategy of the household (Theses; RSCI) // V SB.: international economic Symposium - 2015: Proceedings of the II international scientific and practical conference dedicated to the 75th anniversary of the faculty of Economics of St. Petersburg state University. 22-25 April 2015-St. Petersburg.: Scythia print publishing house, 2015. - P. 402-407.

Belozerov S. A. trends in the development of insurance in the digital economy // Article from the collection of works "Insurance in The digital economy: problems and prospects: proceedings of the XIX international.scientific. - prakt.Conf."(Yoshkar-Ola, 5-7 June 2018) in 2T. T. 1 / Rosgosstrakh: Mari state UN-t: edited by E. V. Zlobin, T. V. Sarycheva. - Yoshkar-Ola: publishing House of Mari state University, 2018. -300 p.

Deyneka O. Dysfunctional Economic Behaviour: Victims of Financial Debt (The Case of Microfinance Organisation Clients) // Psychology and Law in Europe: When West Meets East / Ed. By Pär-Anders Granhag, Ray Bull, Alla Shaboltas, Elena Dozortseva. CRC Press, 2017 P. 125-135

Deyneka O. S. Methodology of economic and psychological research at the Department of political psychology of St. Petersburg state UNIVERSITY. Theory and practice of Russian political psychology // Proceedings of the scientific conference devoted to the Department of political psychology. Edited by Prof. Yuriev A. I.-St. Petersburg: St. Petersburg state University, 2008. - P. 174.

Deyneka O. S. Psychology of economic policy // anthology to the textbook on political psychology. SPb: "Kolo", 2012. - P. 129 -175.

Deyneka O. S. Social regulators as factors of realization of economic power and policy // Psychology of power - 2008: Proceedings of the Second international scientific conference / edited by Yuriev A. I. - SPb., 2008. - Pp. 37-41.

Deyneka O. S., Zabelina E. V. Results of the development of a multiple-factor questionnaire for rapid diagnosis of economic attitudes. Psychological research, 2018, 11(58), 9. 